\title{
Formação continuada de professores dos anos iniciais: "Seminário de Boas Práticas" como proposta de formação e integração docente
}

\author{
Mariana Vaitiekunas Pizarro* \\ Regina Célia dos Santos Nunes Barros ** \\ Marli Aparecida Bartholomae da Silva***
}

\section{Resumo}

Muitos são os estudos que apontam desafios, demandas e necessidades na busca pelo aprimoramento da formação de professores. Buscando romper com a visão de professor que "reproduz sempre as mesmas práticas", o presente estudo objetiva conhecer o posicionamento dos professores sobre uma proposta de formação na escola através da socialização de práticas pedagógicas consideradas bemsucedidas pelos docentes denominada "Seminário de Boas Práticas", bem como avaliar o alcance dessa situação como proposta de formação continuada. A pesquisa, de caráter qualitativo, fez uso de questionários semiestruturados para mapear as percepções dos professores em relação a esta proposta formativa. Os resultados destacam a importância de qualificar o fazer docente para que não se resuma a um fazer destituído de finalidade e crítica, valorizando as ideias dos professores, tendo em vista legitimar os saberes docentes e refinar suas práticas, superando a compreensão do professor como mero executor de tarefas.

Palavras-chave: Formação de professores. Anos Iniciais do Ensino Fundamental. Formação Continuada.

* Doutora em Educação para a Ciência pela Universidade Estadual Paulista Júlio de Mesquita Filho (UNESP/Bauru). Professora do Instituto Federal de Educação, Ciência e Tecnologia do Paraná (IFPR/Londrina).

** Mestra em Educação para a Ciência pela Universidade Estadual Paulista Júlio de Mesquita Filho (UNESP/Bauru). Professora da Secretaria do Estado da Educação de São Paulo (SEESP/Bauru-SP).

*** Graduada em Pedagogia pela Universidade Nove de Julho (Uninove). Professora da Secretaria do Estado da Educação de São Paulo (SEESP/Bauru). 


\section{Introdução}

O debate sobre formação docente é uma preocupação constante na literatura em Educação. Muitos são os trabalhos e estudos que apontam desafios, demandas e necessidades, na constante busca por um aprimoramento da formação de professores, seja no início desta caminhada ou ao longo dela, através de ações de formação continuada. Acreditamos que convidar o professor para dialogar e refletir sobre sua ação contribui, de forma essencial, para o aprofundamento dos saberes adquiridos na experiência e para ações de formação cuja finalidade é validar essas práticas, trazendo para a conversa as pesquisas acadêmicas como propostas que auxiliem neste debate.

Giroux (1997) denuncia que as mudanças propostas aos professores em termos de formação geralmente ignoram a inteligência, o julgamento e a experiência que os professores podem trazer para os debates referentes às reformas educacionais - podemos destacar aqui, no caso brasileiro, as mudanças curriculares recentes - e, quando de fato lhes é oferecida a oportunidade de participar dessas mudanças, eles são reduzidos a técnicos que cumprem determinações decididas por especialistas afastados do cotidiano das salas de aula. Nesse sentido, o pesquisador aponta dois requisitos que devem passar por uma análise cuidadosa quando se fala em formação de professores: primeiro, examinar as forças ideológicas e materiais que tendem a reduzir os professores ao status de técnicos cuja função consiste em administrar e implementar programas que desconsideram objetivos pedagógicos específicos, e, segundo, a necessidade de defender a escola como espaço de desenvolvimento de uma democracia crítica, e os professores como intelectuais transformadores.

Nesse sentido, importa destacar que encarar os professores como intelectuais transformadores também fornece "uma vigorosa crítica teórica das ideologias tecnocráticas e instrumentais subjacentes à teoria educacional que separa a conceitualização, planejamento e organização curricular dos processos de implementação e execução" (GIROUX, 1997, p. 161).

A prática docente, permeada de saberes, fundamenta-se essencialmente no cotidiano das escolas, seja em experiências vividas na condição de professor, tanto por aqueles em formação quanto pelos já formados, ou, até mesmo, enquanto aluno:

[...] uma boa parte do que os professores sabem sobre o ensino, sobre os papeis do professor e sobre como ensinar provém de sua própria história de vida, principalmente de sua socialização enquanto alunos. Os professores são trabalhadores que ficam imersos em seu lugar de trabalho durante aproximadamente 16 anos (em torno de 15.000 horas), antes mesmo de começarem a trabalhar. Essa imersão se expressa em toda uma bagagem de conhecimentos anteriores, de crenças, de representações e de certezas sobre a prática docente. Ora, o que se sabe hoje é que esse legado da socialização escolar permanece forte e estável através do tempo. [...] pode-se dizer que 
uma parte importante da competência profissional dos professores tem raízes em sua história de vida [...]. (TARDIF, 2002, p. 68-69).

Contudo, Leone (2011) também destaca:

o que muito nos inquieta é o fato de os saberes herdados da trajetória pré-profissional serem, frequentemente, tomados pelos professores com grande convicção e, então, utilizados de maneira acrítica e não reflexiva em sua prática pedagógica, sobretudo ao se depararem com situações bastante conflituosas, como as que ocorrem no período de sua inserção profissional no magistério. [...] Como resultado, abrem-se possibilidades de consolidação de práticas reprodutoras dos papéis e das rotinas institucionalizadas na escola, as quais, ao resistirem a uma análise crítica e sistemática, acabam, muitas vezes, por perdurar ao longo de toda a carreira profissional do professor. (LEONE, 2011, p. 59-60).

Valorizando a história de vida e de trabalho dos professores e, ao mesmo tempo, buscando romper com essa visão do senso comum de que o professor dos anos iniciais "reproduz sempre as mesmas formas de alfabetizar e trabalhar", o presente estudo objetiva conhecer o posicionamento dos professores acerca de uma proposta de formação através da socialização de práticas pedagógicas consideradas bem-sucedidas pelos docentes, denominada "Seminário de Boas Práticas", bem como avaliar o alcance dessa situação de formação e integração no que tange à formação continuada de professores nos anos iniciais.

Para colaborar e fundamentar este debate, articulamos nossas reflexões com as discussões sobre os saberes docentes (TARDIF, 2002), as necessidades formativas (LEONE, 2011; MIZUKAMI et al., 2002) e com o rompimento da visão do professor como prático-reflexivo (GHEDIN, 2002; PIMENTA, 2002; ZEICHNER, 2003), avançando na compreensão do professor como intelectual crítico (GIROUX, 1997).

\section{Percurso Metodológico}

Esta pesquisa, de caráter qualitativo (CHIZZOTTI, 1998; LÜDKE; ANDRÉ, 1986) busca compreender, através das respostas dadas a um questionário semiestruturado formulado com perguntas dissertativas, quais as compreensões dos professores sobre a sua formação na escola, bem como em relação à ação formativa denominada "Seminário de Boas Práticas".

Dentro da abordagem qualitativa de pesquisa, Chizzotti (1998, p. 82) apresenta a definição dos papéis de pesquisador e pesquisado e faz questão de destacar que o pesquisador precisa “[...] despojarse de preconceitos, predisposições para assumir uma atitude aberta a todas as manifestações que observa [...]", no entanto alerta que isso não pode significar, de forma alguma, uma "[...] mera 
concessão de um sábio, provisoriamente humilde, para efeitos de pesquisa”. Ao contrário, o pesquisador deve estar imerso na realidade observada, assumi-la com verdade, sem perder de vista que o conhecimento "[...] é uma obra coletiva e que todos os envolvidos na pesquisa podem identificar criticamente seus problemas e suas necessidades, encontrar alternativas e propor estratégias adequadas de ação".

Sobre os pesquisados, o autor destaca uma preocupação: o quanto os sujeitos (no nosso caso em particular, professores), muitas vezes imersos em experiências cotidianas e práticas, têm dificuldade ou pouca oportunidade de estabelecer relações entre os saberes particulares e a totalidade, e de relacionar suas experiências individuais com o contexto geral da sociedade (CHIZZOTTI, 1998, p. 83). Essa fragmentação de percepção da própria ação denuncia a influência de uma racionalidade técnica e instrumental que coloca o professor como mero executor, sem que ele tenha a possibilidade de elevar seus atos e práticas ao nível da reflexão, aqui compreendida como conhecimento crítico sobre suas próprias ações.

O seminário foi uma proposta levada aos professores a partir de uma demanda que surgiu das observações feitas pela Professora Coordenadora da Unidade Escolar, que identificou modelos de boas práticas na atuação de alguns docentes, mas que ficavam limitados à sala de aula ou às conversas informais na sala dos professores.

Para valorizar e, ao mesmo tampo, ampliar a possibilidade de um compartilhamento mais sistematizado dessas práticas, a Coordenação Pedagógica e a Direção resolveram propor uma ação para socializar essas práticas. Foi então solicitado aos professores que selecionassem, entre suas próprias práticas em sala de aula, ao menos uma que mereceria destaque e atenção por parte dos colegas.

Ao propor esta atividade de socialização através do "Seminário de Boas Práticas", a Coordenação Pedagógica almejou ampliar a chance desses procedimentos serem replicados ou até mesmo melhorados pelo próprio grupo e, ao mesmo tempo, buscou alternativas para investir na formação docente a partir das práticas oriundas da sala de aula.

A pesquisa foi feita em uma escola pública estadual que atende alunos do $1^{\circ}$ ao $5^{\circ}$ ano nos anos iniciais do ensino fundamental no interior do estado de São Paulo.

A escola possui quatorze professores (contando os professores de Arte e Educação Física) dos quais treze aceitaram participar, denominados aqui como P1 a P13 para preservar o anonimato garantido na assinatura do Termo de Consentimento Livre e Esclarecido. 


\section{Discussão: o ponto de vista dos professores acerca da formação na escola.}

As professoras que colaboraram com essa pesquisa possuem de nove a vinte e quatro anos de experiência dedicados ao ensino público estadual, e a faixa etária delas varia de trinta a cinquenta e seis anos de idade. Para facilitar a compreensão dos dados, optamos por definir categorias de análise para agrupar respostas afins. Nesse sentido, definimos as seguintes categorias: i) Formação em serviço na escola; ii) Percepções sobre a proposta de Seminário como atividade de formação e socialização; iii) Temas explorados e alunos contemplados; iv) Importância da divulgação da própria prática e contribuição para a formação docente; v) Sugestões. Apresentamos a seguir a análise das falas das professoras.

\section{i) Formação em serviço na escola:}

Todas as professoras consideraram a formação na escola como de muita qualidade, destacando o papel da Direção e da Coordenação Pedagógica em proporcionar estudos e momentos de discussão que fundamentam a prática. Sete professoras (P2; P4; P7; P9, P10, P12 e P13) destacam como ponto negativo o pouco tempo destinado para formações; uma delas sugere, inclusive, a existência de mais um dia de formação:

O grande ponto positivo dessa formação é a interação da equipe gestora, que não mede esforços para selecionar bons textos, tirar dúvidas, solucionar problemas, transmitir informações, etc. O ponto negativo é o pouco tempo destinado para que as professoras organizem suas rotinas, projetos, sequências didáticas com suas colegas de ano/série. Mudança: acrescentar mais um dia de ATPC [Aula de Trabalho Pedagógico]. (P9, grifo nosso).

As mesmas preocupações foram apresentadas por P10:

Trabalho nesta escola desde 2006, durante todo esse tempo a equipe gestora sempre se preocupou com a formação de seus docentes. Priorizou pela qualidade de informações que, uma vez recebidas em capacitações na Diretoria de Ensino, pela Direção ou pelas Coordenadoras Pedagógicas que tivemos até aqui, não se prenderam em passar o que lhes foi delegado, mas se preocuparam em complementar com conteúdos e reflexões sobre os assuntos abordados, nos encontros semanais de ATPC. Em minha opinião, o tempo destinado para esta formação sempre foi um ponto negativo, pois são assuntos que exigem muito mais estudos, reflexões e discussões, afinal estamos em constantes mudanças, quer seja na análise dos Currículos, leitura de documentos, entre outros assuntos.

Já a professora P6 relata não possuir pontos negativos a declarar, mas faz uma sugestão de modalidade de formação docente que parece se adequar a diferentes necessidades, muito embora não 
priorize o encontro coletivo e a troca de experiências: "Não tenho pontos negativos a ressaltar, só sugeriria mais cursos para professores online, com estudos autônomos, onde cada um se aperfeiçoaria de acordo com seu tempo" (P6).

A professora P13 traz um novo elemento para essa discussão da formação na escola:

Como pontos positivos temos as trocas de experiência, a formação de atitudes reflexivas e ampliação de novas teorias e situações didáticas. Como pontos negativos, o pouco tempo destinado a essa formação e falta de parceiros em Universidades Públicas para ajudar nessa formação. (P13).

A questão do pouco tempo destinado à formação dos professores também é apontada por Camargo (2009), que destaca que, da maneira como o tempo tem sido tratado na escola, não traz bons resultados, pois:

Mais fragmentado do que deveria, os professores, em sua maioria, "não dispõem do tempo suficiente para a construção de sua própria competência e do conhecimento com seus alunos. O tempo é uma das razões de angústia para os professores" (PONCE, 2004, p. 99). [...] Exige-se dos professores atividades burocráticas que muitas vezes são desnecessárias a eles, fazendo com que outras atividades importantes sejam deixadas de lado. Ponce (2004, p. 99) lembra que há "um tempo que não abriga a reflexão, mais do que isso, a impede". Se a reflexão precisa fazer parte da atuação profissional de todo educador, não pode ser excluída de forma alguma e o tempo não deve resumir-se em quantidade, mas considerar a qualidade das relações, das ações, dos processos e dos produtos educativos. (CAMARGO, 2009, p. 29).

O dilema do uso do tempo na escola para aprimorar a formação de professores é uma questão essencial e que precisa ser debatida, especialmente no âmbito escolar, que sofre as pressões e os impactos da compreensão do professor como mero executor, compreensão esta que precisa ser superada com urgência.

ii) Percepções sobre a proposta de Seminário como atividade de formação e socialização:

Todas as professoras consideraram o "Seminário de Boas Práticas” uma importante iniciativa de formação docente e pontuaram que, ao longo da elaboração e realização das atividades até a culminância do processo com a realização do Seminário propriamente dito, houve muitas aprendizagens, com destaque para: superação das dificuldades na elaboração de apresentações e no uso de computador e projetor (P2); superação da inibição para falar com os colegas sobre sua própria prática e o reconhecimentos de uma nova forma de compartilhar saberes na Unidade Escolar (P4); reconhecimento da importância do registro (escrito, fotográfico, acervo de trabalhos e materiais produzidos - grifo nosso) para valorizar e avaliar a prática docente e o processo de aprendizagem dos alunos (P9, P10) e dos professores (P1, P3, P5, P6, P8, P11, P12 e P13). 
Merece destaque a fala de P7, quando deixa claro seu receio de receber críticas:

Achei bom, mas não gosto de me expor para não correr risco de ser criticada, pois sempre procuro fazer meu trabalho da melhor maneira possível, justamente para não ouvir críticas, entretanto é a oportunidade de trocarmos experiências e compartilharmos o que deu certo e o que não deu também.

Segundo Tardif e Lessard (2009, p. 1888-189), o individualismo docente é uma postura comum nas escolas e pode ser resultado de pelo menos três fatores: da organização do trabalho, que não permite colaboração; de um conflito entre a necessidade de partilhar coletivamente os custos do ensino e o desejo de guardar para si as recompensas do ensino bem-sucedido; e por fim um desejo de trabalhar coletivamente, que é fragilizado por experiências que não deram certo.

$\mathrm{Na}$ fala de P7, notamos algumas características apontadas por Tardif e Lessard e, ao mesmo tempo, concordamos que esta postura precisa ser respeitada dentro da escola, pois:

De certa maneira, cada professor se considera único nas suas relações com os alunos, pois é bem "ele", esse "si mesmo profissional", que entra em relação com eles; sua personalidade permite estabelecer o "contato". Os custos desse investimento pessoal no trabalho - que pode transformar-se, finalmente, em sofrimentos pessoais e dúvidas importantes relacionadas à sua própria personalidade (sou mesmo feito para essa profissão? Será que eu ensino, realmente, alguma coisa aos jovens? Tenho forças para realizar essa profissão?) - fazem com que o trabalhador se considere pessoalmente responsável pelo seu trabalho, tanto pelos fracassos quanto pelos sucessos. Constata-se mais uma vez como a docência assemelha-se aqui a um trabalho artesanal, a meio caminho entre o trabalho dos operários substituíveis da cadeia de montagem e a atividade dos artistas insubstituíveis na criação da obra. No plano de gestão da organização do trabalho, todos os professores são de certo modo substituíveis, como o mostra, ademais, a grande mobilidade intraprofissional; mas na relação com os alunos e na vida concreta de um estabelecimento, cada professor é uma pessoa única e cuja personalidade conta muito. (TARDIF; LESSARD, 2009, p. 190).

\section{iii) Temas explorados e alunos contemplados:}

Os temas explorados foram os mais diversos, tendo em vista atender às demandas dos alunos de diversos anos: Parlendas (P5), Leitura de ajuste/Leitura compartilhada (P8) e Higiene e Saúde (P12) com os $1^{\text {os }}$ anos; Cantigas de Adoletas (P1), Escrita e revisão de Parlendas e Cantigas (P9) com os $2^{\text {os }}$ anos; Cantando e aprendendo em sala de aula (P6) e A nossa Copa (P7) com os $3^{\circ}$ anos; Roda Literária (P2), $1^{\text {a }}$ página do Jornal (P3), Confabulando com as Fábulas do Programa Ler e Escrever (P4) com os $4^{\mathrm{os}}$ anos; Reforço Escolar e Currículo+ $(\mathrm{P} 13)$ com os $3^{\mathrm{os}}$ e $4^{\mathrm{os}}$ anos; Arte e Educação Física: Bumbameu-boi: música e dança na escola com os $3^{\mathrm{os}}$ e $4^{\mathrm{os}}$ anos (P10, P11). 
Podemos observar que a variedade de temas compartilhados durante o "Seminário de Boas Práticas" ofereceu aos professores a oportunidade de compartilhar práticas, atividades, pontos positivos e negativos de cada intervenção, bem como a ampliação de repertórios sobre como avaliar diante dessas diferentes temáticas.

iv) Importância da divulgação da própria prática e contribuição para a formação docente:

Com relação à divulgação da própria prática para os colegas, todos os professores classificaram essa ação de formação como muito boa, "[...] um momento de novas aprendizagens, reflexão e ação compartilhadas" (P13) e uma “[...] forma eficiente de discriminar boas práticas e apresentar um novo olhar a práticas diferenciadas" (P3).

Além disso, P4 destaca que o professor está em constante formação, e desse modo “[...] o Seminário veio a contribuir para a reflexão sobre as práticas desenvolvidas em consonância com a teoria que recebemos em nossas reuniões de ATPC, bem como em nossa formação acadêmica" (P4). Já o ponto de vista de P5 alerta sobre a relevância de práticas como essa para a formação de professores recém-formados na Universidade ou com pouca experiência de sala de aula, pois "[...] muitos professores começam a lecionar sem a vivência na sala de aula, e isso acaba sendo prejudicial aos alunos".

Em busca da superação da ideia de que os professores dos anos iniciais não arriscam mudanças em suas práticas, P7 destaca que, através da prática de Seminário:

Os professores têm a chance de conhecer outras possíveis maneiras de desenvolver conteúdos muitas vezes já saturados, isto é, trabalhados sempre da mesma maneira. Atividades desenvolvidas com um olhar diferente buscando a aprendizagem e, dentro da aprendizagem, o prazer em aprender.

E P9 avança na reflexão para que a formação docente seja muito mais do que mera burocratização do fazer pedagógico:

Penso que ele [o Seminário - grifo nosso] nos auxilia a entender que o registro burocrático e repetitivo da nossa profissão contribui muito pouco em relação ao registro das boas práticas. Registrar é importante, mas desde que ele tenha função, sentido e significado para os membros envolvidos. Esse momento de compartilhar as práticas é essencial, pois na minha formação universitária vivenciei muita teoria e foi no início, "dando" aula, que aprendi na marra o quê, como, por quê, quando ensinar aos alunos e também aprendi muito, por acerto e erro, como fazer da melhor maneira o meu trabalho e acredito que esse é o pior jeito.

A fala de P9 traz muitos elementos a serem analisados, que nos fazem refletir: a função burocrática de alguns modelos de formação, limitados ao preenchimento de papéis e à escrita de listas e 
mais listas de expectativas de aprendizagem, muito mais relacionados à execução do Currículo do que aos anseios de diferentes realidades escolares; a distância entre a formação na Universidade - que ainda é reconhecida por ser muito mais teórica e distante da prática na escola real - e a realidade de sala de aula; a aprendizagem do professor por "tentativa e erro" e os possíveis efeitos dessas práticas sobre a aprendizagem dos alunos, bem como o reconhecimento, como professora, de que esta não é a melhor maneira de aprender.

Essa fala corrobora a preocupação apontada por Zeichner (2003 apud BARBOSA, 2003, p. 37) sobre a formação de professores enquanto espaço de formar para executar, e não para pensar, criticar e questionar:

É raro os planejadores educacionais, assim como os órgãos do governo, encararem os professores como agentes importantes no processo de reforma educacional. Pelo contrário, a abordagem dominante consiste em treiná-los para que sejam implementadores eficientes de políticas desenvolvidas por outros que nada têm a ver com a sala de aula. Em muitos projetos de reforma educacional de todo o mundo, a meta é ter professores-funcionários irreflexivos e obedientes, que implementem fielmente o currículo prescrito pelo Estado, empregando os métodos de ensino prescritos.

Nesse sentido, a atividade desenvolvida ofereceu aos professores a oportunidade de superar práticas demandadas apenas pelo currículo oficial, compartilhando experiências para além dele, demonstrando que os professores possuem práticas relevantes e que muitas vezes são "escondidas" pela necessidade do cumprimento do currículo através de projetos e sequências didáticas desenvolvidas com foco em implementá-lo.

\section{v) Sugestões:}

O espaço dado aos professores para sugestões foi importante para que eles pudessem se colocar em relação aos próprios Seminários e também em relação à formação que recebem na escola. Dos treze professores, apenas três (P1, P8, P12) não apontaram sugestões.

Os demais professores apontaram nas sugestões: elogios ao trabalho em equipe (P2, P3); o questionário como espaço de reflexão para a prática docente (P4); a privacidade da prática docente como algo a ser superado através de situações de formação que permitam a troca de ideias (P5); a superação de desafios no manuseio de tecnologias e no compartilhamento de práticas (P9, P7).

A professora P10 aproveitou o espaço de sugestões para desabafar sobre as relações estabelecidas na escola e sobre a importância do trabalho em equipe: 
$\mathrm{Na}$ escola, somos sempre uma equipe docente, mas nem sempre atuamos como uma, propriamente. Temos aqueles que apreciam o trabalho do outro e dele vislumbram melhorar o seu e assim crescemos com o outro. Outros, cansados, reclamam e até conseguem nos contaminar com seu mal humor. Podendo contribuir com o grupo, pouco faz, e se faz, contrariado. Lutamos contra um sistema que insiste em nos desestimular e mesmo assim continuamos na tarefa de ensinar e tentar fazer sempre o melhor. Que os mais jovens continuem a chegar à Educação com anseios de ser equipe e fazer a diferença, não para alimentar egos, mas para a prática prazerosa do ensino.

A fala de P10 destaca a importância da colaboração entre professores e da formação de uma verdadeira equipe. Para que isso ocorra, Tardif e Lessard (2009, 185-187) apontam alguns fatores considerados relevantes pelos próprios professores: colaboração para o planejamento de ensino entre professores do mesmo grau e também da mesma matéria ou área de conhecimento; o suporte de um colega de experiência, como uma espécie de mentor informal promovendo um encorajamento aos mais novos; divisão de tarefas pedagógicas; o tamanho da escola e a possibilidade de os professores se relacionarem em mais ou menos oportunidades com os colegas; a estabilidade do grupo de professores e da equipe escolar; a qualidade das relações pessoais na escola, onde a colaboração surge a partir de uma amizade ou a amizade se forma em decorrência dela; e, por fim, um projeto coletivo na escola que possa gerar espírito de equipe.

Avançando na reflexão sobre o trabalho em equipe e a colaboração entre docentes, P13 destaca a importância da parceria entre as escolas públicas e universidades públicas para ampliar e promover formações mais variadas, para além daquelas oferecidas pela Secretaria Estadual da Educação:

A formação do professor deve ser repensada pela SEE; deveria ser disponibilizada uma carga horária maior; manter parcerias com a universidade pública, trazendo os formadores desta no contexto escolar e formando os professores, estimulando os professores a investir em seu desenvolvimento profissional.

Ainda refletindo sobre o papel das universidades nesse processo, P6 destaca uma prática muito comum em relação às pesquisas que buscam a escola como espaço de coleta de dados e reflexão: "Sempre que participo de pesquisas, não tenho um retorno final, o que foi feito? Alguma coisa foi mudada? Para que fim servirá este questionário? Se tiver um resultado final, alguma proposta, mudança; gostaria de ser informada. Obrigada.” (P6)

Sobre o papel da Universidade e sua relação com a escola, Fernandes e Megid Neto (2012) corroboram a visão de P6 e P13 e destacam:

Para que as propostas de inovação se constituam em experiências significativas, há necessidade de se estabelecer uma parceria de fato entre universidade-escola, entre pesquisador, professor-alunos, de modo a envolver todos os participantes em um processo de ação-reflexão-ação. Deve-se levar em consideração as experiências dos professores e alunos, trazendo para o debate os problemas e dificuldades encontrados 
na prática, de maneira que as propostas de inovação sejam configuradas, planejadas e implementadas de modo coletivo e colaborativo. (FERNANDES; MEGID NETO, 2012, p. 658).

As sugestões dos professores demonstram um envolvimento e uma preocupação muito grande com suas práticas e com sua própria formação, bem como uma liberdade de argumentação e clareza de que muito já é feito na escola, mas que o tempo e o espaço sempre podem ser aprimorados em favor de uma constante integração da equipe escolar, bem como de propostas de formação que superem aquelas comumente apresentadas pela rede estadual.

\section{Considerações Finais}

Observando e analisando as respostas dadas pelos professores aos questionários e articulando essas respostas com a literatura, pudemos notar um avanço significativo na compreensão do professor em reconhecer a escola como espaço de formação (LEONE, 2011, MIZUKAMI, 2002; TARDIF, 2002) e também em valorizar a prática dos demais colegas como fonte de aprendizado. Além disso, os professores participantes reconhecem a troca de experiências como uma excelente alternativa de formação, porém avaliam que o tempo destinado à formação na escola é pouco e muitas vezes preenchido por burocracias ou formação para a execução de tarefas.

Pudemos notar a diversidade de temas explorados pelos professores e a variedade de alunos envolvidos e atendidos por essas práticas.

Notamos ainda que os professores assumem a necessidade constante de aprender e apontam a ausência da universidade pública na formação continuada na escola. Como sugestão, reiteram a relevância da presença dessa instituição no espaço escolar, postura esta possivelmente relacionada à saturação dos professores em relação às formações empreendidas pela Secretaria Estadual da Educação, que se dedicam muito mais à implantação do currículo e de seus materiais previamente propostos do que em aprimorar e qualificar a pluralidade de propostas e ideias dos professores em exercício.

Envolvidos com os conhecimentos emergidos da sala de aula e do fazer docente expressos na fala das professoras, concordamos com Ghedin (2002) sobre a importância de qualificar o fazer docente, para que ele não se resuma a um fazer destituído de finalidade e crítica, e a formação na escola deve privilegiar esse movimento:

A experiência docente é espaço gerador e produtor de conhecimento, mas isso não é possível sem uma sistematização que passa por uma postura crítica do educador sobre 
as próprias experiências. Refletir sobre os conteúdos trabalhados, as maneiras como se trabalha, a postura frente aos educandos, frente ao sistema social, político, econômico e cultural é fundamental para se chegar à produção de um saber fundado na experiência. Deste modo, o conhecimento que o educador "transmite" ao educando não é somente aquele produzido por especialistas deste ou daquele campo específico de conhecimento, mas ele próprio se torna um especialista do fazer (teórico-práticoteórico). Fundar e fundamentar o saber docente na práxis (ação-reflexão-ação) é romper com o modelo "tecnicista mecânico" da tradicional divisão do trabalho e impor um novo paradigma epistemológico capaz de emancipar e "autonomizar" não só o educador, mas, olhando-se a si e à própria autonomia, possibilitar a autêntica emancipação dos educandos, não sendo mais um agente formador de mão-de-obra para o mercado, mas o arquiteto da nova sociedade, livre e consciente de seu projeto político. (GHEDIN, 2002, p. 135).

Acreditamos que uma formação continuada de professores que realmente faça sentido para eles precisa compreender as demandas que emergem da sala de aula e valorizar as ideias e pretensões dos professores em relação a sua própria prática e à aprendizagem dos alunos, tendo em vista legitimar os saberes docentes e refinar suas práticas partindo "do chão de sala de aula", superando a compreensão do professor como mero executor de tarefas. 


\section{REFERÊNCIAS}

CAMARGO, M. P. de. Tempo pedagógico e tempo administrativo na formação de professores. Londrina, 2009, 67 fls. Trabalho de Conclusão de Curso (Graduação em Pedagogia) - Universidade Estadual de Londrina, Londrina, 2009.

CHIZZOTTI, A. Pesquisa em ciências humanas e sociais. São Paulo: Cortez, 1998.

FERNANDES, R. C. A.; MEGID NETO, J. Modelos educacionais em 30 pesquisas sobre práticas pedagógicas no ensino de Ciências nos anos iniciais da escolarização. Investigações em Ensino de $\begin{array}{lllllll}\text { Ciências. } & \text { v. } & 17, & \text { n. } & 3, & \text { Disponível }\end{array}$ <http://www.if.ufrgs.br/ienci/artigos/Artigo_ID309/v17_n3_a2012.pdf>. Acesso em: 8 maio 2017.

GHEDIN, E. Professor reflexivo: da dimensão da técnica à autonomia da crítica. In: PIMENTA, S. G.; GHEDIN, E. Professor reflexivo no Brasil: gênese e crítica de um conceito. 2. ed. São Paulo: Cortez, 2002. p. 129-150.

GIROUX, H. A. Os professores como intelectuais: rumo a uma pedagogia crítica da aprendizagem. Porto Alegre: Artes Médicas, 1997.

LEONE, M. N. Necessidades formativas dos professores dos anos iniciais na sua inserção no exercício da docência. 2011. 315 f. Dissertação (Mestrado em Educação) - Faculdade de Ciências e Tecnologia, Universidade Estadual Paulista, Presidente Prudente, 2011.

LÜDKE, M.; ANDRÉ, M. E. D. A. Pesquisa em educação: abordagens qualitativas. São Paulo: EPU, 1986.

MIZUKAMI, M. da G. N. et al. Escola e aprendizagem da docência: processos de investigação e formação. São Carlos: EdUFSCar, 2002.

TARDIF, M. Saberes Docentes e Formação Profissional. 2. ed. Petrópolis: Vozes, 2002.

TARDIF, M; LESSARD, C. O trabalho docente: elementos para uma teoria da docência como profissão de interações humanas. 5. ed. Rio de Janeiro: Vozes, 2009.

ZEICHNER, K. M. Formando professores reflexivos para a educação centrada no aluno: possibilidades e contradições. In: BARBOSA, R. L. L. (Org.) Formação de educadores: desafios e perspectivas. São Paulo: Unesp, 2003. 
Continuing education of teachers in the early

years: "Good Practices Seminar" as a

proposal for teacher education and integration

\begin{abstract}
There are many studies that show challenges, demands and needs in the search for improvement of teacher education. Seeking to break with the teacher's view that "always plays the same practices", the present study aimed to evaluate the placement of teachers on a proposal for training in school through socialization of pedagogical practices considered successful by teachers called "Good Seminar Practices" and to assess the extent of this situation as a proposal for continuing education. The research, qualitative, made use of semi-structured questionnaires to map the perceptions of teachers regarding this formative proposal. The results highlight the importance of qualifying the teacher do to not summarize a make devoid of purpose and criticism, valuing teachers' ideas in order to legitimize the faculty knowledge and refine their practices surpassing the understanding of teacher as mere executor of tasks.
\end{abstract}

Keywords: Teachers Education. Early years of elementary school. Continuing Education.
La educación de los maestros de los años iniciales de la escuela primaria: "Seminario de Buenas Prácticas" como una propuesta para la formación y la integración docente

\section{Resumen}

Hay muchos estudios que muestran desafíos, exigencias y necesidades en la búsqueda de la mejora de la formación docente. Tratando de romper con la opinión de la maestra que "siempre juega las mismas prácticas", el presente estudio tuvo como objetivo evaluar la colocación de los profesores sobre una propuesta de formación en la escuela a través de socialización de prácticas pedagógicas consideradas exitosas por maestros llamada "Buenas Prácticas Seminario" y para evaluar el alcance de esta situación como una propuesta para la formación continua. La investigación cualitativa, hizo uso de cuestionarios semiestructurados para mapear las percepciones de los maestros con respecto a esta propuesta formativa. Los resultados destacan la importancia de la calificación del profesor hacer para no resumir un hacer sin objeto y la crítica, valorar las ideas de los profesores con el fin de legitimar los conocimientos docentes y refinar sus prácticas que superan la comprensión del maestro como un mero ejecutor de tareas.

Palabras-clave: Formación del professorado. Años Iniciales de la escuela primaria. Educación continua.
Mariana Vaitiekunas Pizarro

E-mail: marianavpz@gmail.com

Regina Célia dos Santos Nunes Barros

E-mail: barros.celia@terra.com.br

Marli Aparecida Bartholomae da Silva

E-mail: marlibartholomae@ hotmail.com
Enviado em: 05/05/2016

Versão final recebida em: 08/05/2017

Aprovado em: 10/05/2017 